\title{
Job Burnout and Employee Performance in Hospitality Industry: The Role of Social Capital
}

\author{
Dhyah Harjanti ${ }^{1,2 *}$, Faiz Akbar Todani ${ }^{2}$
}

\begin{abstract}
The hospitality industry is known for its labor-intensive and intense interpersonal interaction characteristics. The high rate of burnout in the hospitality industry has been escalating and become a crucial issue for the management. The burnout can lead to the decline of the employee performance. The previous studies suggested that the happy and cooperative employees tend to deliver a better performance. Since cooperative is one form of the social capital manifestation, this study aims to analyze the role of the social capital in reducing burnout and improving employee performance. The data collection was conducted by distributing questionnaires to all non-daily worker employees at the first-line and middle-line level employees in three budget hotels under the similar chained hotel group in Surabaya. The data were processed using the partial least square analysis technique. The result revealed that the social capital has a significant negative influence on job burnout, but a significant positive influence on employee performance. The result also proves that job burnout has a significant negative influence on employee performance.
\end{abstract}

Keywords: Burnout; employee performance; social capital.

\section{Introduction}

The hospitality industry is known as a laborintensive industry. The intensity of the workforce in the hospitality industry has always been attributed to the irreplaceable role of personal services. Working in the hospitality industry can be tiresome for employees. They face demanding work demands, complex procedures, and intense interpersonal relationships at every stage of their working day (Yirik et al. [1]). Moreover, employees must be responsive to serve customers who have different needs with minimum error rates. Therefore, they are quickly getting burnout. According to Farzianpour et al. [2], manpower's burnout is a psychological syndrome consisting of: a) chronic fatigue, sleep disorders, different physical signs; b) pessimistic and negative tendencies toward colleagues and clients, feeling guilty, cornered, job dissatisfaction; c) feelings of failure and inability, loss of judgment and understanding, feeling pressed and exploited, and loss of performance.

Employees who experience burnout will undoubtedly decrease their work performance. They tend to be passive and pessimistic about completing the work that may cause them to become even more depressed.

\footnotetext{
${ }^{1}$ Faculty of Economic and Business, Department of management, Universitas Airlangga, J. Airlangga 4, Surabaya, Indonesia 60132

${ }^{2}$ Faculty of Economic, Department of management business, Petra Christian University, J. Siwalankerto 121-131, Surabaya, Indonesia 60236

Email: dhyah@petra.ac.id, faizto@gmail.com

* Corresponding author
}

They will also be vulnerable to an illness that may potentially increase their absentee rates as well. Boehm and Lyubomirsky [3] also point out that happy employees show higher levels of performance than unhappy employees do. Happy employees are more sensitive to job opportunities, more involved and helping others, more confident and optimistic (Zelenski et al. [4]).

Furthermore, El-Said [5] states that cooperative attitude is one of the factors that affect and improve employees' performance at the hotel. The cooperative attitude is one dimension of the social capital, which arises because of a certain set of values or informal norms among group members (Bhandari and Yasunobu [6]). The research of Dai et al. [7] also reveals that social capital can improve employee performance. Meanwhile, the social capital that contains the characteristics of mutual trust, common purpose, and a cooperative attitude will improve employees' morale. The existence of such a spirit will boost their performance (Shirom [8]). It can be inferred that employees with high levels of social capital will work harder when trying to do the best for their organizations and colleagues (Hador [9]).

Nahapiet [14] defines social capital as some actual and potential resources embedded in, through, and derived from a network of relationships owned by an individual or a social unit. Unlike the human capital, which is a combination of attributes, skills, and experience of a person, the social capital consists of values and benefits, actual and potential, generated from social interactions with other people (Santarelli and Tran [15]). Social capital cannot be separated from relationships among individuals. As a set of resources derived from relationships, social capital has many different attributes. 
Nahapiet [14] divides social capital into three dimensions, namely: Structural social capital, relational social capital, and cognitive social capital. This research is adopting the social capital dimensions following Nahapiet [14], because this study analyzes the influence of social capital at the individual level within the organization.

The structural social capital is an overall form of relationship between social actors (Nahapiet [14]). This term describes the configuration of impersonal relationships of people or units. According to Nahapiet [14], this dimension refers to the organizational structure, the pattern of connections between individuals, and the relationships that make up the organization's network. This dimension has the meaning that a person's position in the interaction structure will give him certain advantages (Nahapiet [14]), such as the ease of finding jobs, obtaining information, or accessing resources (Tsai [16]).

The relational social capital refers to assets that are rooted in the relationship, such as trust and reliability for trustworthiness (Tsai [16]). Trust is the attribute of a relationship, while reliability for trustworthiness is an attribute of the individuals involved in the relationship (Tsai [16]). This dimension supports the performance cohesion because it reflects mutual trust, togetherness, and caring. This dimension is an asset as it is created and emerging from the relationships among members of the organization that includes beliefs, norms and sanctions, obligations, expectations, and identification (Nahapiet [14]).

The cognitive social capital dimension according to Nahapiet [14] refers to resources that provide representations, interpretations, and systems of shared meanings. This dimension is manifested through attributes such as shared codes or shared paradigms that facilitate a common understanding of common goals and appropriate ways of acting within social systems. This general understanding can be done through collectivity, which has become the main resource of the social capital. This is also added with attributes such as shared vision or equality of values that facilitate individual and collective action and shared an understanding of appropriate action and collective goals. The cognitive dimension includes attributes such as shared norms, action codes, and convergence of views (Zhang et al. [17]). Shared values and visions can foster the development of relationships for mutual trust. Members of the organization with collective goals and values will tend to trust each other because they can expect them to work together to achieve collective goals and will not be impeded or imposed by other members for pursuing self-interest (Tsai [16]).
According to Hafeez and Akbar [18], performance can be interpreted as the achievement of specific tasks that are measured based on predetermined standards or identified with the accuracy, completeness, financing and speed. According to Bakker and Schaufeli [19], every employee in the organization is required to provide a positive contribution through good performance, given the performance of the organization depend on the performance of its employees. Employee performance is critical because it will reflect the organization's performance. Salleh et al. [20] reveal that employees play an essential role in ensuring the effective and efficient implementation of the organization's policies and programs.

Mathis and Jackson [21] suggest four indicators to measure employee performance. We use these indicators because one of the indicators is the cooperation with colleagues, so it correlates with social capital. Besides, within the working environment of the hospitality industry, the ability to work together is one of the critical measurement to assess employee performance. These indicators are as follows: 1) Quality of work; measured from the employee's perception of the quality of work produced and the perfection of tasks compared to the skills and abilities of employees. 2)The quantity of work; measured from the employee's perception of the number of activities assigned and the results. The quantity measurement involves calculating the output of the process or the execution of the activity. 3) Work time; measured from the employee's perception of time for an activity accomplishment compared to the appointed time and the ability to maximize the time available. 4) Cooperation with colleagues; measured from the ability of employees to cooperate with colleagues and the environment. The ability to work together can create cohesiveness so that it can improve the teamwork sense among employees.

Burnout is prolonged stress, demand in the workplace that burdens or exceeds the resources owned by individuals (Buick [22]). Stress refers to a transient adaptation process and is accompanied by mental and physical symptoms, whereas burnout refers to a disturbance in adaptation accompanied by chronic functional impairment (Buick and Thomas [22]). The stress that causes this burnout includes high tension in work, low social support, exposure to workplace violence and intimidation, night shift work demands, high demands at work, poor work organization, ambiguity in decision making in critical situations based on inadequate information (Farzianpour et.al. [2]). Burnout is not a personal matter. It is a social or environmental issue related to one's work (Beckstead [23]).

Baron and Greenberg [24] suggest four indicators for job burnout, while Maslach [25] propose three 
indicators only. The difference happens because Maslach [25] regard physical exhaustion as one of the impacts of burnout, while Baron and Greenberg [24] consider physical exhaustion to be a form of burnout. This study assumes that physical exhaustion is one form of job burnout because employees who are constantly exposed to stresses will be susceptible to illness and poor lifestyle tendencies such as decreased appetite and insomnia. Physical exhaustion does not always appear after a person experiences all types of burnout. It can be felt when employees feel being exploited or perceive their responsibility exceeding their resources.

There are numbers of studies that have investigated the relationship between health, social capital and its components. One study in Canada shows that the social capital manifestation, especially trust, has a significant relationship with reducing depression levels (Sheingold et al. [10]). The phenomenon of the social capital, job burnout and employee performance has been extensively studied in midscale and luxury hotels (Kuruuzum et al. [11], Fiksenbaum et al. [12], Karatepe and Tizabi [13], Yirik et al. [1]). However, there is still an absence of research connecting the social capital, job burnout, and employee performance among budget hotels. Therefore, this study investigates the impact of the social capital on job burnout and employee performance among the employees of some budget hotels in Surabaya. The research focuses on many non-daily workers who are positioned in the first-line and middle level. These non-daily workers are employees who have passed the probationary period or has met the criteria as a contract employee, so their relationship with other co-workers is considered strong, and they are expected to share the same office space.

An atmosphere built on trust, shared values and beliefs can help people to collaborate and make them easier to assess their working conditions by reducing insecurity, uncertainty, and disorientation. These conditions can also improve their performance (Ommen et al. [26]. Social capital can affect the quality of service and output. The existence of social capital between employees will increase their morale to work better. Good social relations among employees will create a comfortable working environment. This work environment is created because of the shared vision and goals among employees that support the performance of employees to cooperate and achieve common goals. Cooperation can be created if the trust is inherent in the parties who trust and believe in the given task. Support from colleagues or superiors also encourages employees to work well. This support is the result of trust and a close network between the parties concerned. Therefore, we propose that social capital positively influences employee performance (H1).
Farzianpour et al. [2] found that social capital has a significant and inverse relationship to burnout which signifies the importance of the social capital role of employees in an organization. Support from colleagues can help employees to cope with stress and reduce the chances of experiencing burnout. Corporate custom as a form of a norm in social capital is also able to reduce burnout caused by the conflict. The manners ignorance can create a less conducive working atmosphere. Moreover, the neglect of etiquette can trigger personal conflicts that are difficult to overcome (Boyas and Wind [27]). Such conflicts can cause emotional exhaustion and depersonalizetion, which is a reflection of burnout. We propose that social capital negatively influences burnout (H2).

Burnout can negatively affect employee attitudes and lead to negative behaviors, such as low work involvement, performance decline, and increased turnover intentions. The negative effects of burnout on employee performance may be lowered effectiveness, work absenteeism, decreased service quality, loss of interest in the organization, family and marital problems, alcohol and drugs consumption, depression and even suicidal tendencies. Therefore, recognizing this syndrome including its effects and preventing the occurrence of this syndrome is very important (Yirik et al. [1] and Farzianpour et al. [2]). Thus, we propose the third hypothesis as: burnout negatively influences employee performance (H3).

\section{Methods}

This study aims to determine the effect of social capital on burnout and employee performance. The population of this study is 51 non-daily workers who are in the first and middle level of three budget hotels under the same chain group in Surabaya. The first-line employees are those who hold the position of ordinary staff, while middle-line employees are those who have the position of supervisor and manager or head of the department. Due to the small population, we use saturated sampling techniques.

The exogenous variable in this research is the social capital (SC). In this study, social capital is defined as collective assets in the form of norms, beliefs, networks that are shared and lead to cooperative and collective actions for mutual benefits. The social capital dimensions are adapted from Nahapiet [14] to measure how strong the social capital among hotel employees is. These dimensions are structural social capital, relational social capital, and cognitive social capital. One example of a structural social capital indicator is "I feel that the work team facilitated me to participate in work activities." 
Table 1. Indicators

\begin{tabular}{|c|c|c|c|}
\hline Variables & Dimensions & Indicators & Source \\
\hline \multicolumn{2}{|c|}{ Social Capital Structural } & Relationship & Nahapiet \\
\hline \multirow[t]{7}{*}{ (SC) } & Social Capital & & [14] \\
\hline & Relational & Mutual trust and & \\
\hline & Social Capital & reliability & \\
\hline & Cognitive & Shared codes & \\
\hline & Social Capital & & \\
\hline & & $\begin{array}{l}\text { Shared norm, } \\
\text { value, and vision }\end{array}$ & \\
\hline & & $\begin{array}{l}\text { Shared } \\
\text { understanding }\end{array}$ & \\
\hline \multirow{8}{*}{\multicolumn{2}{|c|}{ Burnout (BO) }} & Physical & Baron and \\
\hline & & Exhaustion & Greenberg \\
\hline & & Emotional & [24] \\
\hline & & Exhaustion & \\
\hline & & Depersonalization & \\
\hline & & Feeling of Low & \\
\hline & & Personal & \\
\hline & & Accomplishment & \\
\hline \multirow{4}{*}{\multicolumn{2}{|c|}{$\begin{array}{l}\text { Employee } \\
\text { Performance } \\
\text { (EP) }\end{array}$}} & Work Quality & Mathis \\
\hline & & Work Quantity & and \\
\hline & & Timeliness & Jackson \\
\hline & & Cooperativeness & {$[21]$} \\
\hline
\end{tabular}

Table 2. The validity and reliability criteria

\begin{tabular}{ll}
\hline Measurement & Criteria \\
\hline Convergent Validity & Standardized loading factor $>0.4$ \\
Discriminant Validity & AVE $>0.5$ \\
Composite Reliability & $\rho c>0,6$ \\
Cronbach Alpha & $\mathrm{a} \geq 0,5$ \\
\hline
\end{tabular}

The endogenous variables in this study are job burnout and employee performance. We adopt the burnout indicators from Baron and Greenberg [24], which consist of four dimensions. One example of burnout indicator is "In the past month or so, I find it is hard to concentrate". The employee performance indicators adapted from Mathis and Jackson [21] consisting of four indicators. These indicators are quantified as follows: "I can complete the job on time".

In this study, the data were collected by distributing questionnaires using a Likert scale with a scale of 1 (strongly disagree) to 4 (strongly agree). Only a four categories Likert scale is used to avoid respondents' tendency to give neutral answers. Afterwards, the data is analyzed using Partial Least Square (PLS), because it requires relatively small numbers of data and more flexible assumption requirement.

To test the validity and reliability of reflective constructs, we utilize benchmarks as stated in Table 2.

Meanwhile, to examine the validity of the formative construct, the evaluation of the measurement model is based on the significance of T-Statistics of the formative construct. Hence, the validity and reliability test are not needed. To get the T-Statistics value through the bootstrapping process, the TStatistics value should be> 1.96 to be valid. The structural model is evaluated using R-square $\left(R^{2}\right)$ for dependent constructs and T-Statistics for the significance of influence. The criteria are $\mathrm{R}^{2}>0.3$ (very weak), $0.3<\mathrm{R}^{2}<0.5$ (weak), and $0.5<\mathrm{R}^{2}<0.7$ (moderate), and $\mathrm{R}^{2}>0.7$ (strong) (Moore et al. [28]).

In addition to the R-square values, the PLS model is also evaluated using the T-Statistics score to measure the significance of the latent construct influence on other constructs. The size of the significance of TStatistics should be more than 1.96. The level of confidence used is $95 \%$, so the level of precision or inaccuracy limit $\alpha=5 \%$ and yielded a T-Statistics score of 1.96 .

\section{Results and Discussion}

Based on the questionnaire that has been filled by 51 respondents from three budget hotels in Surabaya, most respondents are in the age range of $26-30$ years old (41\%), men (53\%), married (71\%), in the middle-line level management (55\%), length of work $>1$ year (94\%) and at Front Office department (32\%).

Figure 1 shows the result of the outer model that has been constructed and processed. The convergent validity can only measure variables with reflective indicators only, i.e. burnout and employee performance. All loading factors that are related among indicators, and between indicators with variables, have value $>0.4$. Thus, it can be concluded that the indicators and the variables are valid.

Unlike burnout and employee performance, the social capital variable has formative dimensions. Hence, it is not necessary to assess its validity through the loading factor in the outer model, but through T-statistics at inner stage model. On the other hand, the relationship between the indicator statement and its dimensions is reflective, so that it can be measured through the loading factor value. In this study, the structural social capital dimension consists of six indicators, relational social capital dimension consists of seven indicators, and cognitive social capital dimension consists of six indicators. All of them have loading factor values $>0.4$. Thus, all indicators are valid. The test results show that all dimensions of social capital, employee performance, and burnout have AVE value $>0.5$. This means that all reflective variables with indicators along with the three dimensions of social capital meet the standard value of convergent validity. The value of AVE social capital is only 0.297 , but this should not be considered. Since the social capital is a formative variable, the AVE value is not required. 


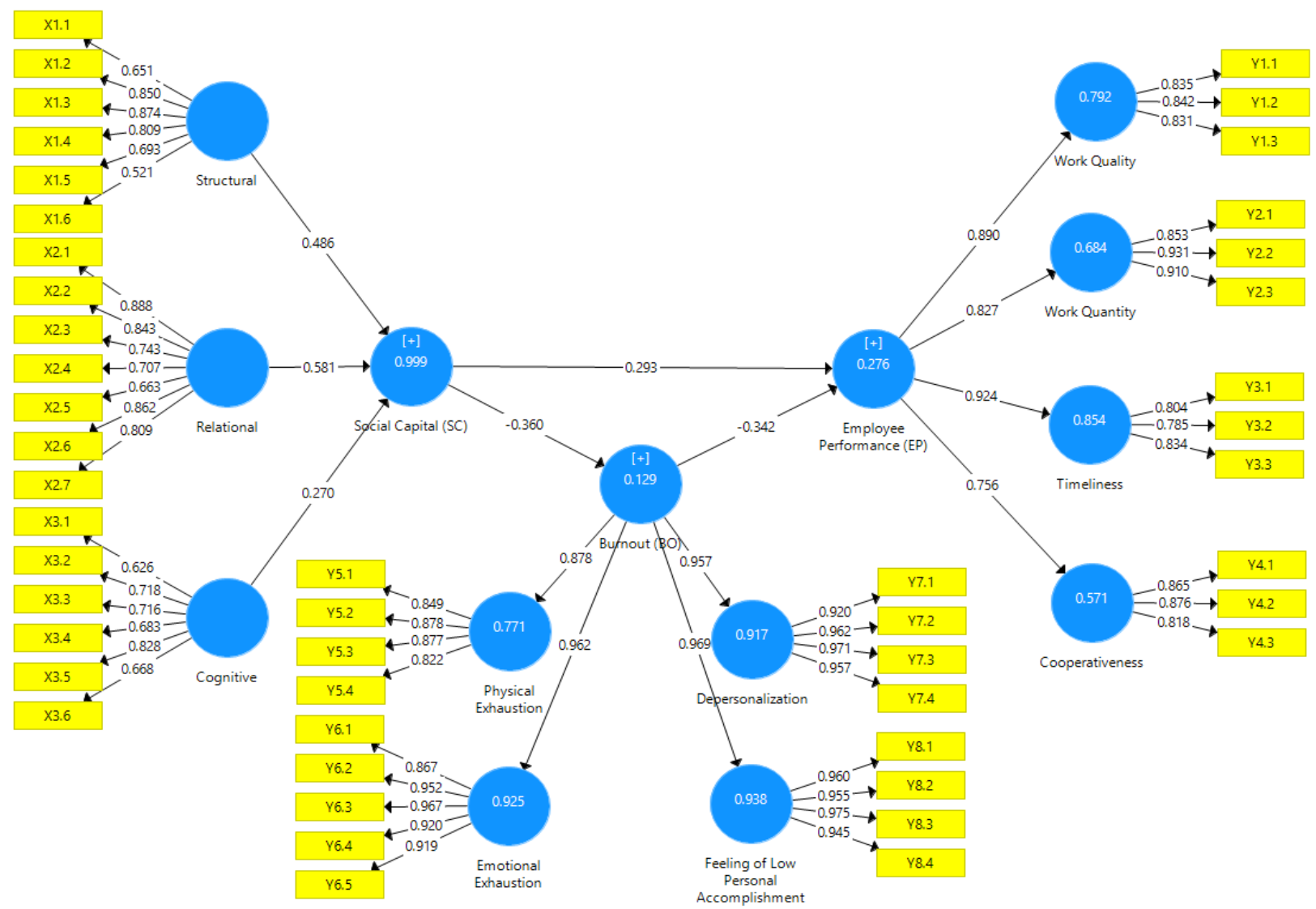

Figure 1. Outer model

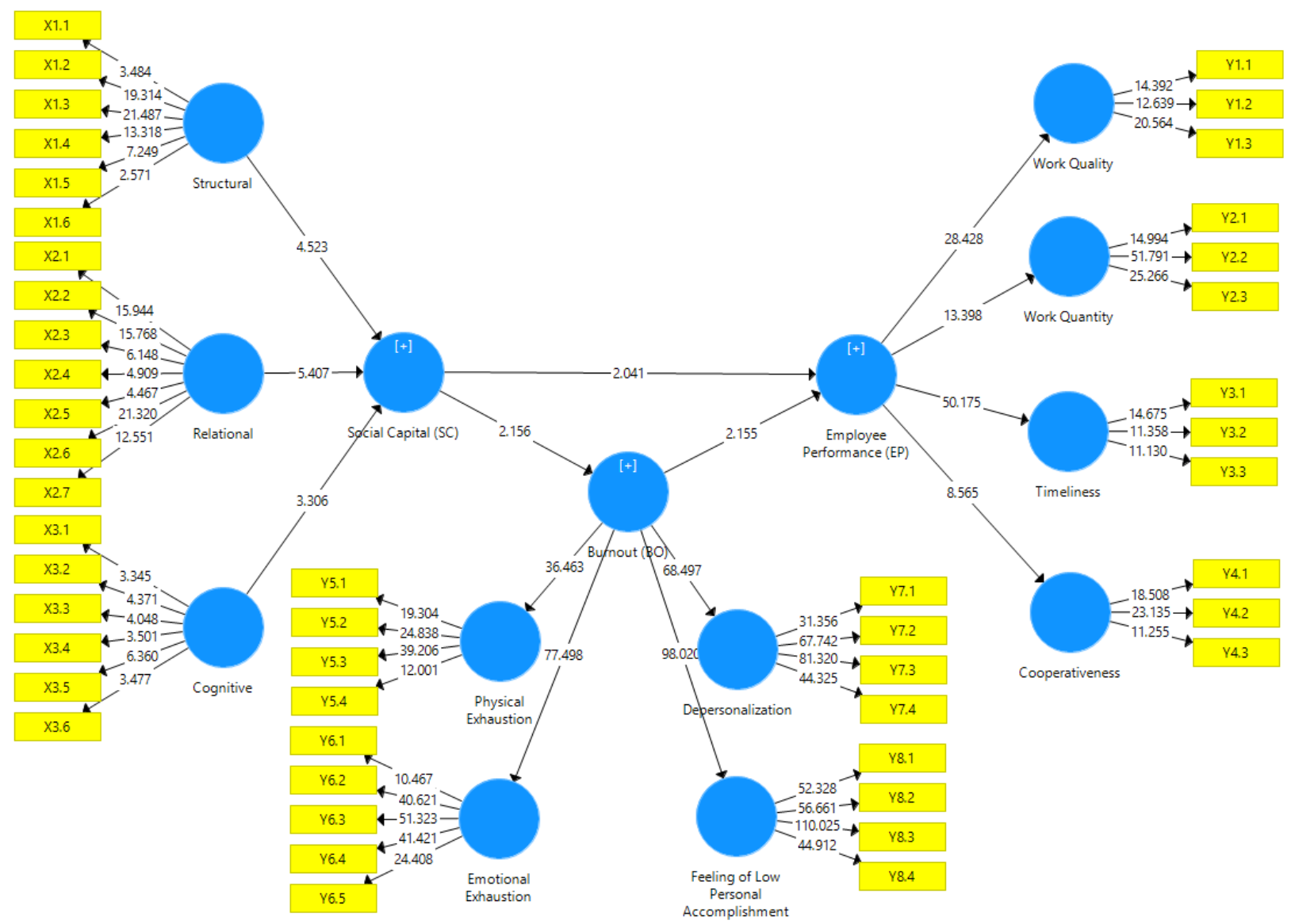

Figure 2. Result of inner model 
Based on the results of discriminant validity test, all values of cross loading construct associated with the indicator is higher than the value of other constructs. Thus, all constructs in this study have met the discriminant validity standard. The result of data processing shows that all constructs have composite reliability value $>0.7$ and Cronbach's alpha $>0.7$. Hence, it is confirmed that all constructs are reliable.

The inner model is tested with bootstrapping and obtained the formative T-statistics value of the construct. In this study, the formative construct is social capital with its three dimensions. The social capital dimensions, namely: structural, relational, and cognitive social capital have T-statistics $>1.96$. Thus, it can be concluded that these three dimensions of social capital are valid.

The next step after testing the outer model is to test the inner model, by evaluating the value of $\mathrm{R}^{2}$ to find out the predictive power of the effects obtained by the endogenous constructs of the exogenous constructs that influence it. Figure 2 shows the inner model that has been constructed and processed to obtain the T-statistics value of each construct.

Table 3 shows that social capital variable has $\mathrm{R}^{2}=$ 0.999 , meaning that the three dimensions of social capital have prediction influence of $99.9 \%$ to the variable that can be categorized strong. All burnout dimensions have $\mathrm{R}^{2}>0.7$, which means that each indicator has a strong influence on its dimension. The employee performance variable gets $\mathrm{R}^{2}=0.276$, which is categorized as very weak. It means that the variable social capital and job burnout bring some influences on the employee performance as much as only $27.6 \%$. The work quality and working time indicators are categorized as strong because the value of $\mathrm{R}^{2}>0.7$. As with the indicators of the quantity of work and cooperation, they are categorized as moderate. The job burnout variable obtains $\mathrm{R}^{2}=0,129$, meaning that the social capital variable predicts to affect the burnout as much as $12.9 \%$ and categorized as very weak.

Then, the hypotheses is tested to find out the influence and the significance among variables. Table 4 shows that all of the T-statistics are above 1.96. Subsequently, it can be stated that all variable relationships are significant.

In this study, the social capital influences employee performance positively and significantly (T-statistics $=2.041)$. The influence is positive, meaning that the increase of the social capital will lead to the increase of the employee performance. This result is in line with Hador [9], which reveals the strong social capital in the workplace making employees feel better, more energized, and eventually bringing an improvement in employee performance.
Table 3. The R-square (R)

\begin{tabular}{lc}
\hline & R Square \\
\hline Social Capital (SC) & 0.999 \\
Burnout (BO) & 0.129 \\
Physical Exhaustion & 0.771 \\
Emotional Exhaustion & 0.925 \\
Depersonalization & 0.917 \\
Feeling of Low Personal Accomplishment & 0.938 \\
Employee Performance (EP) & 0.276 \\
Work Quality & 0.792 \\
Work Quantity & 0.684 \\
Timeliness & 0.854 \\
Cooperativeness & 0.571 \\
\hline
\end{tabular}

Table 4. The hypothesis test

\begin{tabular}{lccc}
\hline & $\begin{array}{c}\text { Regression } \\
\text { Coefficient }\end{array}$ & $\begin{array}{c}\text { T-statistics } \\
(\mid \text { O/STDEV } \mid)\end{array}$ & P Values \\
\hline $\begin{array}{l}\text { Social Capital } \rightarrow \\
\text { Employee Perfor- }\end{array}$ & 0.293 & 2.041 & 0.044 \\
$\begin{array}{l}\text { mance (H1) } \\
\begin{array}{l}\text { Social Capital } \rightarrow \\
\text { Burnout (H2) }\end{array}\end{array}$ & -0.36 & 2.156 & 0.033 \\
$\begin{array}{l}\text { Burnout } \rightarrow \text { Employee } \\
\text { Performance (H3) }\end{array}$ & -0.342 & 2.155 & 0.034 \\
& & & \\
\end{tabular}

The results of the questionnaire show that respondents tend to answer, "Strongly agree" on the social structural dimension indicators. This means that they have an excellent relationship. In the hotel work environment, there is a clear organizational structure and an interconnected work team. The work environment in the hotel requires a highintensity face-to-face interaction with colleagues, even with colleagues from different departments.

As Tsai [16] propose, the structural social capital can stimulate trust representing the relational capital. The people who frequently interact with others will create a more concrete relationship of trust. In addition, they also state that social interaction facilitates the shared goals and values forming within the organization. The daily routine activities, such as morning briefings that bring together the managers of each department to evaluate the work teams, will generate the familiarity and acquaintance between employees. It affects the personal relationships among employees, which is based on the mutual trust and norms established in their relationships. Therefore, it is not surprising that the dimensions of relational social capital and cognitive social capital obtain a high mean value.

The social capital has a negative and significant influence on burnout (original sample $=-0.36$, T-statistics $=2.156$ ). Since most of the respondents choose "disagree" on the burnout indicators, it can be inferred that the issue of burnout in the work environment is minor. One possible explanation for this minor job burnout is due to a high level of the social capital. This is aligned with Farzianpour et al. 
[2] in their research in some teaching hospitals in Iran. The result of this research shows that the social capital, which consists of the mutual trust, the ability to create informal social relationships, the generosity and volunteerism, some variations in interaction, friendship, and leadership; and the community involvement, have a significant inversed relationship to the job burnout.

However, the job burnout variable has the $\mathrm{R}^{2}$ value of 0.129 , which is categorized as very weak. This means that although social capital has a significant influence on burnout, the predicted influence obtained by the job burnout from the social capital is very weak, i.e. $12.9 \%$ only. There are $87.1 \%$ influences from other variables that affect the job burnout not examined in this study.

The low value of the job burnout probably is caused by the employees' satisfactory work experiences. This idea is also revealed by Farzianpour et al. [2] research in some teaching hospitals in Iran. They reveal that the higher the nurse's experience, the less likely the nurse to experience job burnout. In addition, Ang et al. [29] also found that the older nurses and the one with longer working periods had less potential for the job burnout than those of younger age.

The demographic factors such as age, gender and marital status also have some potentials to influence the job burnout. The more mature employees have a lower possibility for the job burnout. Whereas, women and unmarried employees have a higher tendency to experience the job burnout than men do. This is in line with Buick and Thomas [22] who found that the younger, female and unmarried employees are more vulnerable to the burnout. Ang et al. [29] also found that some demographic factors, such as the age and races, influence the burnout. Regarding the demographic profile of respondents that are dominated by a relatively mature, male, and married employee, it is suggested that the demographic factor is a potential contributor to the minor burnout.

The third hypothesis stating that job burnout has an influence on employee performance is accepted ( $\mathrm{T}$ statistics value $=2.155$ ). The value indicates that the burnout has a significant effect on the employee performance. The effect of the job burnout on the employee performance is negative, as shown in the coefficient value which is equal to -0.342 .

This is in accordance to the research of Kuruuzum et al. [11], stating that the job burnout can lead to the decreased work performance, the emergence of a desire to quit the job, the work absenteeism, some family problems, the decreased self-esteem, the difficulty in concentration, the social disengagement, the adverse physical symptoms (such as sleep disturbances, headaches, etc.), the alcohol and drugs consumption, the psychological disorders (such as anger, depression, and apathy). Similarly, Farzianpour et al. [2] point out that the negative effects of the job burnout on employee performance could be in the form of reduced effectiveness, absenteeism, decreased patient satisfaction, family and marital problems, alcohol consumption and drugs, depresssion and even suicidal tendencies.

In the hospitality industry, the job burnout may trigger some poor customer services and increase some potential errors. Ari and Bal [30] support, that the consequences of job burnout include negative behavior toward customers, reduced service quality, the potential for more frequent errors, loss of interest in the organization and work, loss of creativity, job dissatisfaction, poor performance and professional decline in work, procrastinating assignments, and absence.

\section{Conclusion}

Based on the results of the analysis and discussion, it can be concluded as follows: the social capital owned by employees has a significant positive influence on their performance. The social capital owned by employees also affects the job burnout significantly and negatively. The job burnout has a significant negative influence on employee performance.

Based on the results of this study, it is found that the performance of employees in three budget hotels in Surabaya is classified as very good. Although it is still relatively good, from some responses, there is one statement item that gets a relatively low value compared to other statement items. This statement represents the quantity of work, where employees can work on several work tasks simultaneously.

As a budget hotel, where work efficiency is critical, the companies are advised to continue to foster and improve the ability of their employees to achieve efficiency. There are several forms of activities that can be implemented, such as various training to support and hone the ability of employees to do several tasks at once.

\section{References}

1. Yirik, S., Oren, D., and Ekici, R., Determination of Organizational Stress and Organizational Burnout Levels of Mid Level Managers Working in Four and Five Star Hotel Businesses. International Review of Management and Marketing, 5(2), 2015, pp. 52-60. 
2. Farzianpour, F., Fouroshani, A. R., Mohamadi, A., and Hosseini, S. S., Evaluation of the Relationship between Social Capital and Manpower's Burnout in Teaching Hospitals of Iran, African Journal of Business Management, 7(29), 2013, pp. 2872-2881.

3. Boehm, J. K., and Lyubomirsky, S., Does Happiness Promote Career Success? Journal of Career Assessment, 16(1), 2008, pp. 101-116.

4. Zelenski, J. M., Murphy, S. A., and Jenkins, D. A. The Happy-productive Worker Thesis Revisited, Journal of Happiness Studies, 9, 2008, pp. 521537.

5. El-Said, O. A., Impacts of Respect, Support, and Teamwork on Hotel Employees' Morale in Egypt. An International Journal of Tourism and Hospitality Research, 25(2), 2014, pp. 211-227.

6. Bhandari, H., and Yasunobu, K., What is Social Capital? A Comprehensive Review of the Concept, Asian Journal of Social Science, 37(3), 2009, pp. 480-510.

7. Dai, W. D., Mao, Z. E., Zhao, X. R., and Mattila A. S., How does Social Capital Influence the Hospitality Firm's Financial performance? The Moderating Role of Entrepreneurial Activities, International Journal of Hospitality Management, 51, 2015, pp. 42-55.

8. Shirom, A., Burnout and Health: Expanding our Knowledge, Stress and Health, 25, 2009, pp. 281285.

9. Hador, B., How Intra-organizational Social Capital Influences Employee Performance, Journal of Management Development, 35(9), 2016, pp. 11191133.

10. Sheingold, B. H., Hofmeyer, A., and Woolcock, M., Measuring the Nursing Work Environment: Can a Social Capital Framework Add Value? Journal World Medical Health Policy, 4(1), 2012, pp. 1-17.

11. Kuruuzum, A., Anafarta, N., and Irmak, S., Predictors of Burnout among Middle Managers in the Hospitality Industry, International Journal of Contemporary Hospitality Management, 20(2), 2008, pp. 186-198.

12. Fiksenbaum, L., Jeng, W., Koyuncu, M., and Burke, R. J., Work Hours, Work Intensity Satisfactions, and Psychological Well-being among Hotel Managers in China, Cross Cultural Management: An International Journal, 17(1), 2010, pp. 73-93.

13. Karatepe, O. M., and Tizabi, L. Z., Work-related Depression in the Hotel Industry: A Study in the United Arab Emirates, International Journal of Contemporary Hospitality, 23(5), 2011, pp. 608623.

14. Nahapiet, J., Social Capital and Inter-organizational Relations, in Cropper, S., Ebers, M., Huxham, C. and Ring, P.S. (Eds), The Oxford
Handbook of Inter-organizational Relations, Oxford, University Press, Oxford, 2008, pp. 580606.

15. Santarelli, E., and Tran, H. T., Growth of Incumbent Firms and Entrepreneurship in Vietnam. Growth and Change, 43(4), 2012, pp. 638-666.

16. Tsai, W., Knowledge Transfer in Intra-organizational Networks: Effects of Network Position and Absorptive Capacity on Business Unit Innovation and Performance, The Academy of Management Journal, 44(5), 2001, pp. 996-1004

17. Zhang, Y., Kong, F., Chen, H., Jackson, T., Han, L., Meng, J., Yang, Z., Gao, J., Hasan, A. N., Identifying Cognitive Preferences for Attractive Female Faces: An Event-related Potential Experiment using a Study-test Paradigm, Journal of Neuroscience Research, 89, 2011, pp. 18871893.

18. Hafeez, U., and Akbar, W., Impact on Training on Employees' Performance, Business Management and Strategy, 6(1), 2015, pp. 49-64.

19. Bakker, A. B., and Schaufeli, W. B. Positive Organizational Behavior: Engaged Employees in Flourishing Organizations, Journal of Organizational Behaviour, 29(2), 2008, pp. 147-154.

20. Salleh, R., Mishaliny, S. N., and Haryanni, H., Job Satisfaction, Organizational Commitment, and Turnover Intention: A Case Study on Employees of a Retail Company in Malaysia, World Academy of Science, Engineering and Technology, 2012, pp. 316-322.

21. Mathis, R. L., and Jackson, J. H., Human Resource Management, Thirteenth Edition, South Western, Cengage Learning, 2010.

22. Buick, I., and Thomas, M., Why do Middle Managers in Hotel Burnout? International Journal of Contemporary Hospitality Management, 13(6), 2001, pp. 304-309.

23. Beckstead, J. W., Confirmatory Factor Analysis of the Maslach Burnout Inventory among Florida nurses, International Journal of Nursing Studies, 39, 2002, pp. 785-92.

24. Baron, A. R. and Greenberg, J., Organizational Behaviour in Organization: Understanding and Managing the Human Side of Work. Canada: Prentice Hall., 2003.

25. Maslach, C., Job Burnout: New Directions in Research and Intervention, Current Directions in Psychological Science, 12, 2003, pp. 189-192.

26. Ommen, O., Driller, E., Kohler, T., Kowalski, C., Ernstmann, N., Neumann, E., Steffen, P., and Pfaff, H., The Relationship between Social Capital in Hospitals and Physician Job Satisfaction, BMC Health Services Research, 9(81), 2009.

27. Boyas, J., and Wind, L.H., Employment-based Social Capital, Job Stress and Employee Burnout: A Public Child Welfare Employee Structural Model, Children and Youth Services Review, 32, 2010, pp. 380-388. 
28. Moore, D.S., Notz, W.I., and Fligner, M.A., The Basic Practice of Statistics. Sixth Edition. New York: W. H. Freeman and Company, 2013.

29. Ang, S. Y., Dhaliwal, S. S., Ayre, T. C., Uthaman, T., Fong, K. Y., Tien, C. E., Zhou, H., and Della, P., Demographics and personality factors asso- ciated with Burnout among Nurses in a Singapore Tertiary Hospital, BioMed Research International, 2016, pp. 1-12.

30.Ari, S., and Bal, C., The Concept of Burnout: Its Importance for Individuals and Organizations, Management and Economy, 15(1), 2008, pp. 131148. 
Measures of constructs

\section{Appendix}

1. Social Capital

a. Structural social capital

1 I have a good personal relationship with my colleagues.

2 I have a good working relationship with my colleagues.

3 My co-workers and I maintain good personal relationships.

4 My colleagues and I maintain a good working relationship.

5 I feel the work team facilitates me to participate in work activities.

6 I feel the work team facilitates me to participate in activities outside of work.

b. Relational social capital

$7 \quad$ My colleagues and I are willing to help each other if one of us is in trouble.

8 My colleagues and I always try to respect each other.

9 I will tend to keep my distance if my colleagues often behave negatively to me.

10 I feel that colleagues will tend to keep their distance if I often behave negatively to them.

11 My colleagues and I were not easily suspicious when one of us disagreed.

12 My colleagues and I feel that helping a colleague is an obligation.

13 I feel as part of the work team.

c. Cognitive social capital

14 I feel that my colleagues have the same view of life as me.

15 I understand ethical and unethical things in relationships with colleagues.

16 I have goals that are in line with the company's shared goals.

17 I feel the work team often agrees on what is in the best interests of our relationship.

18 I am able to understand the language and terms used in communicating with my work team.

19 I am able to communicate with the same language and terms with my work team.

\section{Employee Performance}

a. Quality of work

1 I always do my work carefully.

2 I was able to complete the task well.

3 I am sure my work assignments are in accordance with the expertise that I have.

4 I can do several tasks at once.

b. Quantity of Work

5 I was able to complete some jobs the company had set.

6 I consider the target of the work given according to my ability.

c. Work Time

7 I was able to complete the task on time.

8 I did not delay the completion of my work assignments.

9 I am obedient to the predetermined target time for completing tasks.

d. Collaboration with colleagues

10 I feel my work team can work in a compact manner.

11 I can work in a team.

12 I feel the completion of work assignments will be better if done together.

\section{Burnout}

a. Physical exhaustion

1 In the past month or so, I have continued to feel tired in completing work.

2 In the past month or so, I continue to feel headaches when facing work assignments.

3 In the past month or so, I continue to experience sleep disorders.

4 In the past month or so, I felt there was a change in my diet.

b. Emotional exhaustion

5 In the past month or so, I have continued to feel anxious.

6 In the last month or so, I lost the enthusiasm to do daily activities.

7 In the last month or so, I found it difficult to concentrate.

8 In the past month or so, I found it difficult to get out of the problem I was facing.

9 In the past month or so, I always felt like I was working in compulsion.

c. Depersonalization

10 In the past month or so, I did not care about colleagues who were facing work problems.

11 In the past month or so, I often ignore conversations when colleagues start the conversation.

12 In the past month or so, I feel reluctant to socialize with colleagues.

13 In the past month or so, I feel reluctant to work in teams.

d. Feeling of Low Personal Accomplishment

14 In the past month or so, I feel unable to complete work tasks.

15 In the past month or so, I felt insecure about developing my competencies.

16 In the past month or so, I feel pessimistic about the goals that I will achieve.

17 In the past month or so, I felt that I would never be able to achieve success in the future. 